\title{
Effectiveness of Structured Counseling and Preventive Strategies in Promoting Awareness and Expressed Habitual Practices Toward Prevention of Urinary Tract Infection Among Women of Reproductive Age Group: A Pilot Study
}

\author{
Sonia Karen Liz Sequera ${ }^{1}$ Leena Kunnath Chacko $^{2}$ \\ ${ }^{1}$ Department of Community Health Nursing, Father Muller College of \\ Nursing, Mangalore, Karnataka, India \\ 2 Yenepoya Nursing College, Yenepoya Deemed to be University, \\ Mangalore, Karnataka, India \\ J Health Allied Sci ${ }^{\mathrm{NU}}$ 2022;12:286-295.
}

Address for correspondence Sonia Karen Liz Sequera, Department of Community Health Nursing, Father Muller College of Nursing, Mangaluru 575002, Karnataka, India (e-mail: soniakaren@fathermuller.in).

\begin{abstract}
Keywords

- SCAPS

- urinary tract infection block randomization

- awareness

- expressed habitual practice
\end{abstract}

Objectives Urinary tract infection (UTI) is the most common infection that affects half of all women in their lifetime and one-fourth have recurrent infections. Health behaviors could prevent the recurrence of UTIs and therefore motivation and increasing awareness are necessary for healthy behavior change. This study was done to evaluate the effectiveness of structured counseling and preventive strategies (SCAPS) in promoting awareness and expressed habitual practices among the women of the reproductive age group to prevent UTI.

Materials and Methods Block randomization with multiple interventions and followup were conducted among 60 women (30 in each group, randomly assigned using the SNOSE technique) attending the OBG and urology OPDs of a selected medical college hospital. Purposive sampling was used to select the subjects. Women who were positive for urine culture and experiencing typical symptoms of UTI, as assessed using the symptom score checklist, were recruited for the study. Pre-test awareness was assessed using a structured awareness questionnaire and a rating scale for expressed habitual practice. After the pre-test, on the same day, the experimental group received SCAPS intervention followed by a second session during the third month. At the third (before the second session) and the sixth-month post-tests were conducted by delivering the same tool to determine the post-test level of awareness and expressed habitual practice after the administration of SCAPS.

Results The study shows there is a significant difference in the awareness and expressed habitual practice values in the experimental group $(p<0.005)$. The effectiveness of SCAPS showed that the mean \pm standard deviation (SD) pre-test score of women (awareness $-\bar{x}_{1} \pm S D=9.47 \pm 2.57$, hygienic habitual practice $-\bar{x}_{1} \pm S D=20.93$ published online January 6, 2022
DOI https://doi.org/ $10.1055 / \mathrm{s}-0041-1740332$ ISSN 2582-4287.

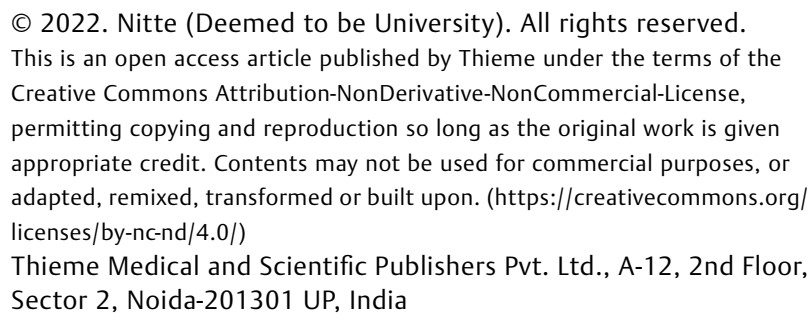

(C) 2022. Nitte (Deemed to be University). All rights reserved. This is an open access article published by Thieme under the terms of the Creative Commons Attribution-NonDerivative-NonCommercial-License, permitting copying and reproduction so long as the original work is given appropriate credit. Contents may not be used for commercial purposes, or adapted, remixed, transformed or built upon. (https://creativecommons.org/ licenses/by-nc-nd/4.0/) Thieme Medical and Scientific Publishers Pvt. Ltd., A-12, 2nd Floor, Sector 2, Noida-201301 UP, India 
\pm 1.91 , fluid and dietary practice $-\bar{x}_{1} \pm S D=7.73 \pm 2.18$ and sexual habits $-\bar{x}_{1} \pm S D=$ $8.00 \pm 3.33$ ) was significantly lower than the mean $\pm S D$ post-test scores (awareness $\overline{\mathrm{x}}_{2} \pm \mathrm{SD}=11.37 \pm 1.65$, awareness $-\overline{\mathrm{x}}_{3} \pm \mathrm{SD}=12.00 \pm 1.05$ ), (hygienic habitual practice $-\bar{x}_{2} \pm S D=22.57 \pm 2.16, \bar{x}_{3} \pm S D=23.90 \pm 1.99$ ), (fluid and dietary practice $-\bar{x}_{2} \pm S D$ $=10.07 \pm 2.21, \bar{x}_{3} \pm S D=11.97 \pm 1.79$ ) and (sexual habits $-\bar{x}_{2} \pm S D=8.81 \pm 2.51$, $\left.\overline{\mathrm{x}}_{3} \pm \mathrm{SD}=9.81 \pm 2.26\right)$.

Conclusion SCAPS was found to be effective on awareness and preventive habitual practices with regard to UTI. SCAPS can be recommended for vulnerable groups such as females so that UTI could be prevented.

Trial Registration CTRI/2018/10/016064 (Registration on 17/10/2018).

\section{Introduction}

Urinary tract infection (UTI) is one of the major problems in developing countries. ${ }^{1}$ It is a common infection among females, with a high incidence among women of reproductive age group. ${ }^{2}$ UTIs can upset any part of the urinary system and usually causes a significant burden among the individuals and are associated with high health care and social costs. $^{3,4}$ UTI has been the major cause of morbidity and mortality among the Indian population. ${ }^{3}$ Moreover, annually 150 million people are suffering worldwide along with a rise in health care cost of at least 6 million dollars, making it necessary to divert the attention to this disease. ${ }^{5}$

UTI is more frequently encountered as an outpatient infection, with a lifetime incidence of 50 to $60 \%$ in adult women. ${ }^{6}$ Due to UTI, every year, nearly 6 to 7 million young women visit physicians, and therefore it is a major concern for healthcare providers. ${ }^{3}$ A study conducted in Tamil Nadu revealed the prevalence of UTI to be $20.4 \%$ among females of the reproductive age group. It is found that nearly 25 to $30 \%$ of women between 20 and 40 years of age will get UTIs. ${ }^{7}$ Another study conducted in Mangalore in 2020 revealed that a total of $13.4 \%$ of women experienced UTI in their lifetime. ${ }^{3}$ The incidence of infection in females increases directly with sexual activity and childbearing. In addition, 50 to $60 \%$ of women (15-49 years) have a history of at least a single episode of UTI, and recurrence within 6 months is very common among women. ${ }^{8}$ Compared with boys, the recurrence rate is $50 \%$ greater in girls. ${ }^{3}$ Malnutrition, poor body and personal hygiene, and increased sexual activity are the most common risk factors for UTIs. ${ }^{4,9}$ Among adolescent girls, poor hygiene and dysfunctional voiding pattern increase the risk for UTI. Silent UTIs may occur among adolescent girls due to inadequate intake of water and infrequent passage of urine. ${ }^{3}$

UTI is limited to the lower urinary tract system, which is known as uncomplicated UTI and is the most common who have normal, unobstructed genitourinary tract, and are healthy premenopausal or non-pregnant women. ${ }^{4}$ UTI is caused by microbes including bacteria, fungi, and viruses. ${ }^{4}$ Escherichia coli accounts for $\sim 75$ to $95 \%$ of all infections. ${ }^{8}$ Any delay in the treatment leads to permanent kidney damage, bacterial endocarditis, and infertility. ${ }^{3}$
A study from Chitradurga revealed that the female students confessed an indiscriminate consumption of antibiotics whenever they fell sick or difficulty while micturition is noticed. ${ }^{10}$ A study conducted in Bangalore showed that one in seven women given antibiotics returned within 28 days for further treatment. ${ }^{11}$ In contrast, studies have shown that the morale and quality of life are affected due to the presence of UTI. ${ }^{12,13}$

Early identification of the disease by proper diagnostic measures and management will help prevent the complications of UTI. Preventive measures such as maintenance of good hygiene during menstruation, intake of more amount of water, also will help reduce the incidence of UTIs. ${ }^{14}$ Appropriate education and other promotional measures by health care professionals play a vital role in the prevention of UTI.

Education can change behavior and will encourage and empower women to accept and perform voluntary healthy behaviors. Women just need assistance and training for changing their health behaviors. ${ }^{4}$ It is a convenient tool for all health care professionals in helping women obtain beneficial health behaviors and change risky lifestyles in terms of health. ${ }^{5}$

A quasi-experimental study conducted in Saudi Arabia revealed that women showed mean scores of pre-intervention deficient, incorrect knowledge, and unsatisfactory selfcare practices regarding their urinary tract infection symptoms. Statistically significant improvements in the total scores were found at the post-test and 3 months later compared with pre-intervention scores $(p<0.001)$. Furthermore, there was an obvious improvement and relief of UTI symptoms as reported by women after the implementation of the instructional program. ${ }^{15}$ Some other studies found that $32.3 \%$ had recurrent urinary tract infection, 19.5\% sample had adequate knowledge about urinary tract infection, $42 \%$ had moderate knowledge, and $35.5 \%$ had poor knowledge. ${ }^{1}$ Reports show that 80 to $95 \%$ of health problems could be managed and prevented at home. ${ }^{16}$

The investigator felt that SCAPS will assist increase the self-care abilities of women throughout their life span. This will in turn develop the confidence by increasing the awareness and motivating them to develop healthy habitual practices, thereby reducing the morbidity and mortality due to UTI. 


\section{Materials and Methods}

\section{Study Design, Setting, Eligibility Criteria, and Participants}

A quantitative research approach with education- and counseling-based block randomization control trial with multiple interventions and follow-up was adopted to find the effect of SCAPS on awareness and habitual practices of women belonging to the reproductive age group visiting the OBG and urology OPDs of a selected medical college hospital. Subjects were recruited using the purposive sampling technique.

Inclusion criteria included women between 18 and 45 years, literate (reading and writing ability in Kannada or English), accessible throughout the study, residing within Dakshina Kannada district (Mangalore), and had access to SMS (mobile) and/or WhatsApp. The exclusion criteria included women with hearing/visual impairment, unconscious women, diagnosed with a major mental disorder, congenital defects of the urinary system, pregnancy, menopause, or hysterectomy.

Data were collected from April 2019 to March 2020. Women, who visited the outpatient department of the hospital for a consultation, were routinely sent for urine analysis based on their presenting complaints. Sixty-one women tested positive for urine culture and who met the study criteria were further interviewed using the UTI Symptom score checklist (UTI-SSC) to assess the typical symptoms of UTI (part 1: included 4-point rating scale with the highest score of 27 and the lowest score of 0 ), its severity (part 2: included 4-point rating scale with the highest score of 27 and the lowest score of 0 ) and the urine analysis report (part 3). Thereafter, women were randomly assigned into experimental and control groups on a rolling enrolment basis using the SNOSE technique.

The sample size was calculated based on the prevalence of UTI in the study conducted by Das and Banerjee, which was $9.77 \%$ in $2014 .{ }^{17}$ The formula used for sample size calculation was $n=\frac{Z^{2} P(1-P)}{d^{2}}$ with a precision rate of $5 \%$ and an attrition rate of $15 \%$. The sample size of each group was found to be 150 . Also, $10 \%$ of the actual sample size was taken keeping 15 as the minimum in each group.

\section{Ethical Permission}

Ethical clearance was obtained from the Institutional Review Committee (IRC no. IRC/FMCON/2018/FAC - 15) and the Institutional Ethics Committee of Father Muller charitable institutions (FMMCIEC/CCM/479/2018). The study was registered under CTRI with registration number CTRI/2018/10/016064. Prior permission was obtained from the authorities of the medical college hospital to conduct the study.

\section{Tools for Data Collection}

UTI symptom score checklist (UTI-SSC) included three sections. Part 1 included nine typical symptoms of UTI, part 2 assessed the severity of the symptoms of UTI, and part 3 included results of urine analysis such as urine characteristics, urine microscopy, and culture.

Others included a socio-demographic questionnaire with 10 items, an awareness questionnaire regarding urinary tract infection (UTI) covering two domains-basics of UTI comprising questions from 1-7 and preventive aspects toward UTI from questions 8 to 14 . Total awareness questionnaire comprised 14 multiple-choice questions. The maximum possible score was 14 . To assess the expressed habitual practice, a three-point rating scale (with scores 0,1 , and 2) was used that covered three domains-the hygienic practices from question 1-14, fluid and dietary habits from questions 15 to 21 , and sexual practices from questions 22 to 28 . The maximum possible score was 56.

All tools of data collection, including the SCAPS intervention, were validated by 14 experts from the field of Medicine (two urologists) and Nursing (four from the Department of Medical and Surgical, two from OBG Nursing, and six from the Department of Community Health Nursing).

The content validity index (CVI) was $>0.7$ and the scale content validity (SVI) was $>0.9$.

The reliability of the tool was done on 20 subjects. Stability (intraclass correlation coefficient, $r>0.9$ ) and internal consistency, (Chronbach's $\alpha, r>0.7$ ) revealed that the tool was reliable. Face-to-face interview technique was used to assess the UTI symptom score checklist and self-reported techniques were used for the other tools during data collection.

\section{Data Collection Methods and Description of SCAPS}

Block randomization with multiple interventions and follow-up was used for the study. The SNOSE technique was adopted for the allocation of subjects to the experimental and control groups. Blocks of 4 (three times) consisting of six possible permutations were taken. A block was chosen randomly (flipping the coin) and the subjects were given randomly selected one opaque envelope from the block available with the investigator. If the paper inside the envelope had a letter written as "E," women were recruited to the experimental group and if written as " $\mathrm{C}$," then women were recruited to the control group. The whole process of permutation and allocation was done by a non-researcher and then handed over one by one to the investigator.

A pre-test was administered to both the groups ( 30 experimental and 31 control). The experimental group received SCAPS immediately after the pre-test that included face-to-face therapeutic counseling, followed by a goal-setting snake and ladder-an indoor game, designed aiming to help them familiarize themselves with a healthy lifestyle. Other components included education and training using technology (images and content on UTI prevention) and a video designed by the investigator and later the case scenarios were discussed. The follow-up was done in the first, second, fourth, and fifth months through supportive telephonic conversations, reminders, and messages through WhatsApp. The first post-test was collected in the third month, followed by a second set of counseling sessions, 


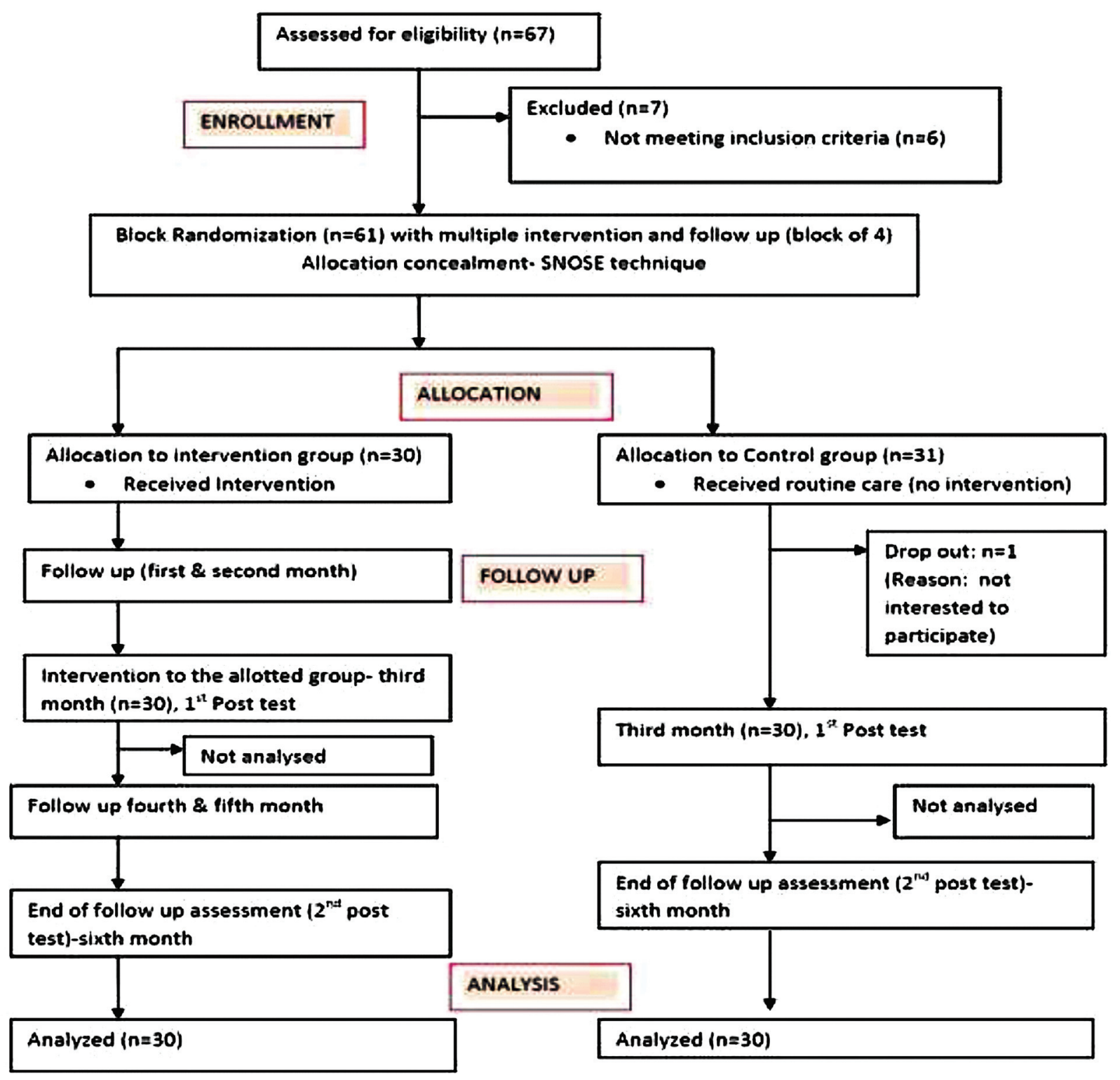

Fig. 1 Consort flow diagram of participants during the study.

and strategies to improve problem-solving skills and prevent UTIs were also used. The second post-test was collected in the 6th month.

The control group received routine care such as antibiotics and analgesics, and basic preventive techniques were advised by the consultant. After the study, an education video was shown to the control group along with information on the prevention of UTI ( $\mathbf{- F i g . 1}$ ).

\section{Statistical Analysis}

Data were analyzed using IBM SPSS Statistics for version 23. Data that followed normality, parametric tests such as " $t$ " test, repeated measures of analysis of variance (ANOVA), Bonferroni post hoc test, analysis of covariance (ANCOVA), and Karl Pearson correlation were used. For the data without normality, Mann-Whitney $U$ test was used to compare between the groups. The level of significance was considered at 0.05 .

\section{Results}

\section{Baseline Information}

The mean age of women was $28.43 \pm 5.1$ years in the experimental group and $27.76 \pm 4.6$ years in the control group ( $p=0.114$-homogeneity).

Other specifications of the units under study are presented in - Table 1.

The mean and standard deviation score of typical symptoms of UTI was $10.80 \pm 4.26$ (in the experimental group) and $13.60 \pm 6.14$ (in the control group).

In the experimental group, 29 (96.7\%) experienced burning micturition, 17 (56.7\%) had fever, 17 (56.7\%) had no bladder control, 4 (13.3\%) experienced hematuria. In the control group, 30 (100\%) experienced burning micturition, 16 (53.3\%) had fever, 21 (70\%) experienced no bladder control, and 9 (30\%) experienced hematuria. 
Table 1 Baseline characteristics of the subjects $n=30+30$

\begin{tabular}{|c|c|c|c|c|}
\hline \multicolumn{2}{|l|}{ Variable } & \multicolumn{2}{|l|}{ Group } & \multirow[t]{3}{*}{$p$-Value } \\
\hline & & \multirow{2}{*}{$\begin{array}{l}\text { Experimental group } \\
(n=30) \\
f(\%)\end{array}$} & \multirow{2}{*}{$\begin{array}{l}\text { Control group } \\
(n=30) \\
f(\%) \\
\end{array}$} & \\
\hline & & & & \\
\hline \multirow[t]{5}{*}{ Education } & Postgraduate & $2(6.7)$ & $2(6.7)$ & \multirow{5}{*}{$\begin{array}{l}0.497 \text { (NS) } \\
\text { Fisher's exact test }\end{array}$} \\
\hline & Graduate & $17(56.7)$ & $13(43.3)$ & \\
\hline & PUC/diploma & $8(26.7)$ & $7(23.3)$ & \\
\hline & High school & $2(6.7)$ & $7(23.3)$ & \\
\hline & Primary & $1(3.3)$ & $1(3.3)$ & \\
\hline \multirow[t]{4}{*}{ Marital status } & Married & $16(53.3)$ & $16(53.3)$ & \multirow{4}{*}{$\begin{array}{l}0.341 \text { (NS) } \\
\text { Fisher's exact test }\end{array}$} \\
\hline & Single & $14(46.7)$ & $12(40.0)$ & \\
\hline & Separated & $0(0.0)$ & $0(0.0)$ & \\
\hline & Widow/widower & $0(0.0)$ & $2(6.7)$ & \\
\hline \multirow{3}{*}{$\begin{array}{l}\text { Number of times } \\
\text { experienced UTI }\end{array}$} & Only once & $14(46.7)$ & $9(30.0)$ & \multirow{3}{*}{$\begin{array}{l}x^{2}=2.059, p=0.357 \\
\text { d.f-2 (NS) }\end{array}$} \\
\hline & $2-3$ times & $12(40.0)$ & $14(46.7)$ & \\
\hline & $>3$ times & $4(13.3)$ & $7(23.3)$ & \\
\hline \multirow{5}{*}{$\begin{array}{l}\text { Source of } \\
\text { information }\end{array}$} & Media & $1(3.3)$ & $2(6.7)$ & \multirow{5}{*}{$\begin{array}{l}0.807 \text { (NS) } \\
\text { Fisher's exact test }\end{array}$} \\
\hline & Relatives/friends & $4(13.3)$ & $6(20.0)$ & \\
\hline & Health personnel & $21(70.0)$ & $19(63.3)$ & \\
\hline & Magazines & $0(0.0)$ & $0(0.0)$ & \\
\hline & Never received information & $4(13.3)$ & $3(10.0)$ & \\
\hline
\end{tabular}

The characteristics of urine in women having UTI in the experimental and control groups are shown in - Table 2.

\section{Evaluation of Intervention}

Section 1: Awareness of UTI

The effectiveness of SCAPS showed that the mean \pm SD of a pre-test awareness score of women $\left(\bar{x}_{1} \pm S D=9.47 \pm 2.57\right)$ was significantly lower than the mean \pm SD of post-test awareness scores $\left(\overline{\mathrm{x}}_{2} \pm \mathrm{SD}=11.37 \pm 1.65, \quad \overline{\mathrm{x}}_{3} \pm \mathrm{SD}=\right.$ $12.00 \pm 1.05)$.

In the awareness of UTI, a significant difference in the pretest and post-test values was found in the experimental group $(\mathrm{F}=32.05, \mathrm{df}=2,58) p<0.05$, whereas, no difference was found in the control group at various time points $(\mathrm{F}=0.70, \mathrm{df}=2,58) p>0.05$. Paired eta square showed $\left(\eta^{2}\right.$ value-0.525) a moderate effect of the SCAPS on overall awareness toward UTI prevention (-Table $\mathbf{3}$ ).

Post hoc analysis was further done and the Bonferroni correction showed a statistically significant difference at 0.05 level of significance. In the total awareness of UTI among the experimental group, significant difference was found between pre-test and post-test $1(p=0.0001)$, pre-test and post-test $2(p=0.0001)$, and post-test 1 and post-test 2 $(p=0.032)$. The result stated that the SCAPS intervention was effective.

Results using MANOVA also showed that there was a significant association between the education $(p<0.451)$, occupation $(p<0.000)$, and type of family $(p<0.010)$ with a level of awareness of women with UTI.

\section{Section 2: Expressed Habitual Practice toward UTI Prevention}

The study shows there was a significant difference in the expressed habitual practice values in the experimental group $(p<0.005)$. The effectiveness of SCAPS showed that the mean \pm SD of the pre-test score of women (hygienic habitual practice $-\overline{\mathrm{x}}_{1} \pm \mathrm{SD}=20.93 \pm 1.91$, fluid and dietary practice $\overline{\mathrm{x}}_{1} \pm \mathrm{SD}=7.73 \pm 2.18$, and sexual habits $-\overline{\mathrm{x}}_{1} \pm \mathrm{SD}=$ $8.00 \pm 3.33$ ) was significantly lower than the mean \pm SD of the post-test scores (hygienic habitual practice - $\overline{\mathrm{x}}_{2} \pm \mathrm{SD}$ $=22.57 \pm 2.16, \overline{\mathrm{x}}_{3} \pm \mathrm{SD}=23.90 \pm 1.99$ ), (fluid and dietary practice $-\overline{\mathrm{x}}_{2} \pm \mathrm{SD}=10.07 \pm 2.21, \overline{\mathrm{x}}_{3} \pm \mathrm{SD}=11.97 \pm 1.79$, and (sexual habits $-\overline{\mathrm{x}}_{2} \pm \mathrm{SD}=8.81 \pm 2.51, \overline{\mathrm{x}}_{3} \pm \mathrm{SD}=9.81 \pm 2.26$ ).

- Table 4 shows there was a significant difference in the pre-test and post-test values of expressed habitual practices in the intervention group (domain $1: \mathrm{F}=51.77$, df-2,28, $p<0.05$ ), (domain 2: $\mathrm{F}=54.74, \mathrm{df}=2,58, p<0.05$ ), (domain 3: $\mathrm{F}=13.98, \mathrm{df}=2,30, p<0.05)$. The paired eta square showed $\left(\eta^{2}\right.$ value-0.641, 0.654, and 0.482$)$ moderate effect of SCAPS on expressed habitual practices (three domains such as hygienic practice, fluid, and dietary practices and sexual practices, respectively).

In post hoc analysis, a significant difference was seen in the pre-test and post-test $1(p=0.000)$, pre-test and post-test $2(p=0.000)$ and post-test 1 and post-test $2(p=0.0001)$ in 
Table 2 Characteristics of Urine of women with UTI in frequency and percentage $n=30+30$

\begin{tabular}{|c|c|c|c|c|c|}
\hline & & \multicolumn{4}{|c|}{ Group } \\
\hline & & \multicolumn{2}{|c|}{ Experimental group } & \multicolumn{2}{|c|}{ Control group } \\
\hline & & $f$ & $\%$ & $f$ & $\%$ \\
\hline \multirow[t]{2}{*}{ Cloudy urine } & yes & 26 & 86.7 & 20 & 66.7 \\
\hline & No & 4 & 13.3 & 10 & 33.3 \\
\hline \multirow[t]{2}{*}{ Smell of urine } & yes & 18 & 60.0 & 15 & 50.0 \\
\hline & No & 12 & 40.0 & 15 & 50.0 \\
\hline \multirow[t]{2}{*}{ Urine microscopy (pus cells) } & Yes & 25 & 83.3 & 28 & 93.3 \\
\hline & No & 5 & 16.7 & 2 & 6.7 \\
\hline \multirow[t]{2}{*}{ Leukocytes } & yes & 16 & 53.3 & 27 & 90.0 \\
\hline & No & 14 & 46.7 & 3 & 10.0 \\
\hline \multirow[t]{2}{*}{ Nitrates in urine } & yes & 15 & 50.0 & 9 & 30.0 \\
\hline & No & 15 & 50.0 & 21 & 70.0 \\
\hline \multirow[t]{2}{*}{ Urine culture report: Organisms } & E-coli & 23 & 76.6 & 27 & 90 \\
\hline & Klebshilla & 7 & 23.4 & 3 & 10 \\
\hline
\end{tabular}

Table 3 Comparison of awareness scores within the group at various time points (ANOVA) $n=30+30$

\begin{tabular}{|l|l|l|l|l|l|l|}
\hline Group & & Mean \pm SD & F-value & D.F & $p$-Value & Effect size \\
\hline Experimental & Pre-test & $9.47 \pm 2.57$ & 32.05 & 2 and 58 & $0.000^{\text {a }}$ & 0.525 \\
\hline & Post-test 1 & $11.37 \pm 1.65$ & & & & \\
\hline & Post-test 2 & $12.00 \pm 1.05$ & & & & \\
\hline Control & Pre-test & $8.57 \pm 2.81$ & 0.70 & 2 and 58 & 0.502 & 0.024 \\
\hline & Post-test 1 & $8.93 \pm 2.32$ & & & & \\
\hline & Post-test 2 & $8.77 \pm 2.50$ & & & & \\
\hline
\end{tabular}

${ }^{\mathrm{a}} p<0.05=$ significant.

the domain 1 of experimental group. Significant difference was also found between pre-test and post-test $1(p=0.0000)$ and pre-test and post-test $2(p=0.000)$, post-test 1 and posttest $2(p=0.000)$ in the domain 2 of the experimental group. In the domain 3 of experimental group, significant difference is found between pre-test and post-test $1(p=0.022)$, pretest and post-test $2(p=0.004)$, and post-test 1 and post-test $2(p=0.007)$. SCAPS intervention was effective in improving the expressed habitual practice of women in preventing UTI.

Results using MANOVA also showed a significant association between the occupation $(p<0.055)$, marital status $(p<0.014)$, and history of diseases $(p<0.004)$ with the expressed habitual practice (domain 3 ) of women with UTI.

- Table 5 shows a comparison of awareness and habitual practice scores between the experimental and control groups using Mann-Whitney's test.

- Table 5 shows that there was a highly significant difference between the experimental and control group scores $(p<0.05)$. The differences occurred in all domains of awareness and expressed habitual practice scores and in favor of the experimental group. This reflects that SCAPS was effective in increasing awareness and expressed habitual practice.
Furthermore, Pearson correlation coefficient results showed no significant relationship between awareness and expressed habitual practice $(p>0.005)$.

\section{Discussion}

One of the very common health conditions that affect many women in their reproductive age group is UTI. Self-care is an important tool and the use of healthy habitual practices and coping skills for promoting their own health helps in preventing or limiting disease and maintaining well-being. ${ }^{15}$

The present study throws light on the effectiveness of SCAPS on awareness and expressed habitual practices of women toward preventing UTI. The results confirmed the positive effect of SCAPS; however, the durability of their awareness and practice remained the same over a period of time.

In the present study, the mean age of women was $28.43 \pm 5.1$ years. This result is consistent with a study conducted by Ahmed et al in Saudi Arabia that reported that the mean age of the study sample was $29 \pm 9.89$, where about half of women's age ranged between 20 and 30 years. ${ }^{15}$ 
Table 4 Comparison of expressed habitual practice scores within the group at various time points (ANOVA) $n=30+30$

\begin{tabular}{|c|c|c|c|c|c|c|c|}
\hline Parameters & Group & & Mean \pm SD & F value & D.F & $p$-Value & Effect size \\
\hline \multirow{6}{*}{$\begin{array}{l}\text { (Hygienic practices in } \\
\text { prevention of UTI) } \\
\text { Domain } 1\end{array}$} & \multirow{3}{*}{$\begin{array}{l}\text { Experimental } \\
n=30\end{array}$} & Pre-test & $20.93 \pm 1.91$ & \multirow[t]{3}{*}{51.77} & \multirow[t]{3}{*}{2 and 58} & \multirow[t]{3}{*}{$0.000^{\mathrm{a}}$} & \multirow[t]{3}{*}{0.641} \\
\hline & & Post-test 1 & $22.57 \pm 2.16$ & & & & \\
\hline & & Post-test 2 & $23.90 \pm 1.99$ & & & & \\
\hline & \multirow{3}{*}{$\begin{array}{l}\text { Control } \\
n=30\end{array}$} & Pre-test & $22.00 \pm 2.30$ & \multirow[t]{3}{*}{0.72} & \multirow[t]{3}{*}{2 and 58} & \multirow[t]{3}{*}{0.493} & \multirow[t]{3}{*}{0.024} \\
\hline & & Post-test 1 & $21.53 \pm 2.06$ & & & & \\
\hline & & Post-test 2 & $21.73 \pm 1.76$ & & & & \\
\hline \multirow{6}{*}{$\begin{array}{l}\text { (Fluid intake and dietary } \\
\text { practices in UTI prevention) } \\
\text { Domain } 2\end{array}$} & \multirow{3}{*}{$\begin{array}{l}\text { Experimental } \\
n=30\end{array}$} & Pre-test & $7.73 \pm 2.18$ & \multirow[t]{3}{*}{54.74} & \multirow[t]{3}{*}{2 and 58} & \multirow[t]{3}{*}{$0.000^{\mathrm{a}}$} & \multirow[t]{3}{*}{0.654} \\
\hline & & Post-test 1 & $10.07 \pm 2.21$ & & & & \\
\hline & & Post-test 2 & $11.97 \pm 1.79$ & & & & \\
\hline & \multirow{3}{*}{$\begin{array}{l}\text { Control } \\
n=30\end{array}$} & Pre-test & $8.93 \pm 2.10$ & \multirow[t]{3}{*}{1.29} & \multirow[t]{3}{*}{2 and 58} & \multirow[t]{3}{*}{0.282} & \multirow[t]{3}{*}{0.043} \\
\hline & & Post-test 1 & $8.73 \pm 2.08$ & & & & \\
\hline & & Post-test 2 & $8.37 \pm 2.62$ & & & & \\
\hline \multirow{6}{*}{$\begin{array}{l}\text { (Sexual habits) } \\
\text { Domain } 3 \\
\text { Experimental }\left(n_{1}=16\right) \\
\text { Control }\left(n_{1}=13\right)\end{array}$} & \multirow{3}{*}{$\begin{array}{l}\text { Experimental } \\
\left(n_{1}=16\right)\end{array}$} & Pre-test & $8.00 \pm 3.33$ & \multirow[t]{3}{*}{13.98} & \multirow[t]{3}{*}{2 and 30} & \multirow[t]{3}{*}{$0.000^{\mathrm{a}}$} & \multirow[t]{3}{*}{0.482} \\
\hline & & Post-test 1 & $8.81 \pm 2.51$ & & & & \\
\hline & & Post-test 2 & $9.81 \pm 2.26$ & & & & \\
\hline & \multirow{3}{*}{$\begin{array}{l}\text { Control } \\
\left(n_{1}=13\right)\end{array}$} & Pre-test & $9.69 \pm 2.72$ & \multirow[t]{3}{*}{1.55} & \multirow[t]{3}{*}{2 and 24} & \multirow[t]{3}{*}{0.233} & \multirow[t]{3}{*}{0.114} \\
\hline & & Post-test 1 & $9.38 \pm 2.50$ & & & & \\
\hline & & Post-test 2 & $9.00 \pm 1.47$ & & & & \\
\hline
\end{tabular}

${ }^{\mathrm{a}} p<0.05=$ significant

This result is also supported by Kodikara et al who reported that of women diagnosed with UTI, $60 \%$ belonged to the age group of 20 to 30 years. ${ }^{18}$ This result is consistent with a study by Millar et al who reported that a higher percentage of UTI among women was found within the age group of 20 to 29 years. $^{19}$

In this study, of women in the experimental group, (12) $40 \%$ experienced UTI, 2 to 3 times, and (4) $13.3 \%$ women experienced UTI more than thrice. In the control group, (14) $46.7 \%$ of women experienced UTI 2 to 3 times, and 7 (23.3\%) experienced UTI more than thrice. This result is supported by a study conducted by Sequera et al, which reported that a total of $13.4 \%$ experienced UTI in their lifetime. Out of 11,1 (9.1\%) experienced UTI more than thrice, 6 (54.5\%) experienced 2 to 3 times UTI, and 4 (36.4\%) experienced UTI only once. $^{3}$ A similar study was conducted at the medical university of Jos (Nigeria) among the 185 female students residing in the hostel, and the results revealed that $34.9 \%$ experienced UTI at some point in their lifetime. ${ }^{20}$ Another study by Ahmed et al showed congruent results that reported that $36(85.71 \%)$ had a previous history of UTI. ${ }^{15}$ This shows that UTI is commonly found in the women of reproductive age group.

In the present study, the mean and standard deviation of typical symptoms of UTI was $10.80 \pm 4.26$ (in the intervention group) and $13.60 \pm 6.14$ (in the control group). In the experimental group, 29 (96.7\%) women experienced burning micturition, 17 (56.7\%) had a fever, 17 (56.7\%) had no bladder control, 4 (13.3\%) experienced hematuria. In the control group, 30 (100\%) women experienced burning micturition,
16 (53.3\%) had a fever, 21 (70\%) experienced no bladder control, and 9 (30\%) experienced hematuria. This study is congruent to the study conducted at Saudi Arabia that showed that 15 (35.7\%), women experienced fever, 39 (92.8\%) experienced dysuria, 37 (88.09\%) experienced urgency, and 28 (66.6\%) experienced incontinence. ${ }^{15}$

In this study, there was a significant difference in the pretest and post-test awareness values in the experimental group $(\mathrm{F}=32.05, \mathrm{df}=2,58) p<0.05$, whereas, no difference was found in the control group at various time points $(\mathrm{F}=0.70, \mathrm{df}=2,58) \quad p>0.05$. Paired eta square shows 0.525 , which is a moderate effect of the SCAPS on overall awareness toward UTI prevention. Significant difference was also found in the pre-test and post-test values of expressed habitual practices in the intervention group (domain $1: \mathrm{F}=$ 51.77, df-2,28, $p<0.05$ ), (domain 2: $\mathrm{F}=54.74$, $\mathrm{df}=2,58$, $p<0.05$ ), (domain 3: $\mathrm{F}=13.98, \mathrm{df}=2,30, p<0.05$ ). The paired eta square shows $0.641,0.654$, and 0.482 which is a moderate effect of SCAPS on expressed habitual practices (three domains such as hygienic practice, fluid, and dietary practices and sexual practices, respectively).

In a similar study conducted in Saudi Arabia, there was a significant improvement in the knowledge of women immediately after the intervention and 3 months later $(p<0.001)$. Significant improvements were shown in women's total scores of knowledge from poor or weak score levels to good levels regarding most of the studied items. The items that demonstrated significant improvements after implementation of the intervention were related to causes, signs, and symptoms, risk factors of UTI, problems associated with 
Table 5 Comparison of awareness and expressed habitual practice scores between the experimental and control group $n=30+30$

\begin{tabular}{|c|c|c|c|c|c|c|c|}
\hline & & Group & $\begin{array}{l}\text { Mean } \\
\text { difference }\end{array}$ & $\begin{array}{l}\text { S.D of } \\
\text { difference }\end{array}$ & $\begin{array}{l}\text { MW test } \\
Z \text { value }\end{array}$ & $p$-Value & \\
\hline \multirow{6}{*}{$\begin{array}{l}\text { Awareness of UTI } \\
\text { (total) }\end{array}$} & \multirow{2}{*}{$\begin{array}{l}\text { Pre- test - } \\
\text { Post-test } 1\end{array}$} & Experimental & -1.900 & 1.900 & \multirow[t]{2}{*}{3.387} & \multirow[t]{2}{*}{0.001} & \multirow[t]{2}{*}{$\mathrm{HS}$} \\
\hline & & Control & -0.367 & 1.033 & & & \\
\hline & \multirow{2}{*}{$\begin{array}{l}\text { Pre-test - } \\
\text { Post -test } 2\end{array}$} & Experimental & -2.533 & 2.129 & \multirow[t]{2}{*}{4.338} & \multirow[t]{2}{*}{0.000} & \multirow[t]{2}{*}{$\mathrm{HS}$} \\
\hline & & Control & -0.200 & 1.990 & & & \\
\hline & \multirow[t]{2}{*}{ Post- test 1 -Post- test 2} & Experimental & -0.633 & 1.273 & \multirow[t]{2}{*}{2.274} & \multirow[t]{2}{*}{0.023} & \multirow[t]{2}{*}{ sig } \\
\hline & & Control & 0.167 & 1.913 & & & \\
\hline \multirow{6}{*}{$\begin{array}{l}\text { Awareness of UTI } \\
\text { (basics of urinary tract } \\
\text { infection) } \\
\text { Domain } 1\end{array}$} & \multirow{2}{*}{$\begin{array}{l}\text { Pre- test - } \\
\text { Post-test } 1\end{array}$} & Experimental & -1.133 & 1.279 & \multirow[t]{2}{*}{2.465} & \multirow[t]{2}{*}{0.014} & \multirow[t]{2}{*}{$\operatorname{sig}$} \\
\hline & & Control & -0.300 & 0.952 & & & \\
\hline & \multirow{2}{*}{$\begin{array}{l}\text { Pre-test - } \\
\text { Post- test } 2\end{array}$} & Experimental & -1.600 & 1.499 & \multirow[t]{2}{*}{4.066} & \multirow[t]{2}{*}{0.000} & \multirow[t]{2}{*}{$\mathrm{HS}$} \\
\hline & & Control & -0.167 & 1.053 & & & \\
\hline & \multirow[t]{2}{*}{ Post- test 1 -Post- test 2} & Experimental & -0.467 & 0.937 & \multirow[t]{2}{*}{1.998} & \multirow[t]{2}{*}{0.046} & \multirow[t]{2}{*}{ sig } \\
\hline & & Control & 0.133 & 1.332 & & & \\
\hline \multirow{6}{*}{$\begin{array}{l}\text { Awareness of UTI } \\
\text { (remedial measures } \\
\text { toward UTI prevention) } \\
\text { Domain } 2\end{array}$} & Pre- test - & Experimental & -0.767 & 1.478 & 2.348 & 0.019 & $\operatorname{sig}$ \\
\hline & Post -test 1 & Control & -0.067 & 0.691 & & & \\
\hline & Pre-test - & Experimental & -0.933 & 1.552 & 2.621 & 0.009 & $\mathrm{HS}$ \\
\hline & & Control & -0.033 & 1.299 & & & \\
\hline & Post-test 1-Post-test 2 & Experimental & -0.167 & 0.648 & 1.070 & 0.285 & NS \\
\hline & & Control & 0.033 & 1.129 & & & \\
\hline Expressed habitual practice & Pre-test - & Experimental & -1.633 & 1.790 & 4.888 & 0.000 & $\mathrm{HS}$ \\
\hline $\begin{array}{l}\text { (hygienic practices in } \\
\text { prevention of UTI) }\end{array}$ & Post-test 1 & Control & 0.467 & 1.137 & & & \\
\hline Domain 1 & Pre-test - & Experimental & -2.967 & 1.752 & 4.949 & 0.000 & $\mathrm{HS}$ \\
\hline & Post-test 2 & Control & 0.267 & 2.664 & & & \\
\hline & Post-test 1-Post-test 2 & Experimental & -1.333 & 1.184 & 3.136 & 0.002 & $\mathrm{HS}$ \\
\hline & & Control & -0.200 & 2.325 & & & \\
\hline Expressed habitual practice & Pre-test - & Experimental & -2.333 & 2.412 & 4.648 & 0.000 & $\mathrm{HS}$ \\
\hline $\begin{array}{l}\text { (fluid intake and } \\
\text { dietary practices }\end{array}$ & Post-test 1 & Control & 0.200 & 0.484 & & & \\
\hline in UTI prevention) & Pre -test - & Experimental & -4.233 & 2.473 & 5.744 & 0.000 & $\mathrm{HS}$ \\
\hline Domain 2 & Post -test 2 & Control & 0.567 & 2.431 & & & \\
\hline & Post- test 1-Post- test 2 & Experimental & -1.900 & 1.689 & 4.655 & 0.000 & $\mathrm{HS}$ \\
\hline & & Control & 0.367 & 2.312 & & & \\
\hline Expressed habitual & Pre-test- & Experimental & -0.813 & 1.047 & 3.415 & 0.001 & $\mathrm{HS}$ \\
\hline $\begin{array}{l}\text { practice } \\
\text { (sexual habits) }\end{array}$ & est 1 & Control & 0.308 & 0.630 & & & \\
\hline Domain 3 & Pre-test- & Experimental & -1.813 & 1.834 & 3.121 & 0.002 & $\mathrm{HS}$ \\
\hline $\begin{array}{l}\text { Experimental }\left(n_{1}=16\right) \\
\text { Control }\left(n_{1}=13\right)\end{array}$ & Post-test 2 & Control & 0.692 & 1.750 & & & \\
\hline & Post-test 1-Post-test 2 & Experimental & -1.000 & 1.095 & 2.491 & 0.013 & $\operatorname{sig}$ \\
\hline & & Control & 0.385 & 1.609 & & & \\
\hline
\end{tabular}

UTI, and also the preventive and management self-care measures to relieve UTI symptoms. ${ }^{15}$ Another study conducted by Heydari et al showed that the mean scores in all aspects of behavior in the intervention group were significantly increased $(p<0.05){ }^{5}$ These findings were congruent with the present study.
In this study, there was a highly significant difference in the awareness and expressed habitual practice scores between experimental and control groups $(p<0.05)$. These findings are in congruent to the study conducted in Iran where a significant increase in the intervention groups' behavior was found compared with the control group. This 
showed a positive impact of education on the mean scores of behavior. $^{5}$

The improvement in the present study refers to the effect of SCAPS given to the women to improve their awareness and change their behavior, enhance and upgrade their self-care practices to relieve their UTI symptoms. UTI can be reduced by following healthy measures such as developing a habit of urinating as soon as the need is felt and emptying the bladder completely when you urinate.

Urinating before and after intercourse, avoiding intercourse while being treated for a UTI, after urinating keeping the genital area clean, avoid using strong soaps, antiseptic creams, feminine hygiene sprays, and powders. The findings of the present study are in line with a supporting study conducted by Hill et al who noted that the measures that reduced the risk of UTI were the use of condoms, voiding after sexual contact, and the type of underwear used, personal hygiene methods used after voiding or defecating, and whether one takes a bath or shower. ${ }^{21}$

In this study, improvement in awareness and habitual practice in the experimental group was due to the SCAPS intervention that sensitized the women toward the prevention of UTI. The program includes various components such as therapeutic counseling at the initial opening and throughout the process to build rapport and trust, open communication, and mutual understanding. Snake and ladder game as a motivational factor to change lifestyle, educational video on UTI, and its prevention to deliver instructions effectively, case scenarios, and discussion to learn with a real-life situation.

After the intervention along with the instructed guidelines for women regarding the awareness and healthy selfcare practices, a significant positive effect on their habitual practices was evident by study findings. This study recognized the need to raise awareness regarding UTI and motivate women for healthy habitual practices in the prevention of UTI. Counseling, as well as motivational sessions, help to inculcate healthy self-care practices to prevent UTI.

Also, a similar study conducted by Heydari et al recommended and advised the importance of education on the health behaviors of women. The use of this method is useful to change their behaviors in preventing UTI. ${ }^{5}$ This study highlighted that there was a lack of women's awareness regarding the concept of self-care practice as well as basic health practices. However, the need to raise awareness regarding UTIs and expand services for prevention and treatment for women as well as health education to learn about self-care practices during UTIs are crucial.

The strength of this study is that the design of the SCAPS for the prevention of UTI among women of the reproductive age group was based on need-based assessment (pre-test) and scientific reviews. The intervention was given at two points, with a gap of 3 months interval.

The study had some limitations. The most obvious limitation was the collection of information using self-report. This study was delimited to a hospital-based study. There was one drop out of the subject in the control group by the end of the second month.
Furthermore, to generalize the result to a wider extent, the efficiency and effectiveness of intervention could be assessed in other settings (clinics, offices, hostels, and colleges, etc.), among women, and the follow-up could be extended for 1 year.

\section{Conclusion}

To conclude, although this study is not uncommon, it yielded enough and very useful information to initiate and develop health intervention measures for the prevention and control of UTI and also showed a positive impact of structured counseling and preventive strategies (SCAPS) on the awareness and expressed habitual practices in women of reproductive age group.

Therefore, due to the high incidence of UTI in women and the positive impact of such interventions, the need to hold SCAPS in meetings, such as women's self-help group, Sthree Shakthi, and other social gathering places of women is emphasized to change their health behaviors. SCAPS proved to be the need of the hour among the women. Appropriate problem-solving skills will empower women to take corrective and preventive steps toward UTI prevention. SCAPS would also act as a barrier to prevent the recurrence of UTI.

\section{Conflict of Interest}

None declared.

\section{Acknowledgments}

The authors would like to acknowledge the support of Father Muller Charitable Institutions, Mangalore, Karnataka, India. The Principal, Father Muller College of Nursing, teaching faculty, experts for their guidance, and participants of the study for their wholehearted participation.

\section{References}

1 Raj A, James J, Jimmy J, Mariya S, Ananda S. Knowledge and self reported practices regarding prevention of urinary tract infection among adolescents girls in selected college of Mangaluru. European Journal of Molecular \& Clinical Medicine [Internet] 2020;11 (07):4515-4519

2 Vigila Christy R, Athinarayanan G, Mariselvam R, Dhasarathan P, Ranjitsingh AJA. Epidemiology of urinary tract infection in South India. World Journal of Biology Pharmacy and Health Sciences 2020;1(01):025-032

3 Sequera KLS, Chacko LK, Pereira PS. Urinary tract infectionknowledge and habitual practices among adolescent girls residing in college hostel of Mangaluru, India: a cross-sectional study. J Clin Diagn Res 2021;15(07):5

4 Javaheri Tehrani F, Nikpour S, Haji Kazemi EA, Sanaie N, Shariat Panahi SA. The effect of education based on health belief model on health beliefs of women with urinary tract infection. Int J Community Based Nurs Midwifery 2014;2(01):2-11

5 Heydari N, Jahanbin I, Ghodsbin F. Urinary tract infection preventive behaviors among adolescent girls: a quasi-experimental study. Journal of Research and Health [Internet] 2019;9(04): 330-336

6 Medina M, Castillo-Pino E. An introduction to the epidemiology and burden of urinary tract infections. Ther Adv Urol 2019; $11: 1756287219832172$ 
7 Muthulakshmi M, Gopalakrishnan S. Study on urinary tract infection among females of reproductive age group in a rural area of Kancheepuram district, Tamil Nadu. Int J Community Med Public Health 2017;4(10):3915

8 Al-Badr A, Al-Shaikh G. Recurrent urinary tract infections management in women: a review. Sultan Qaboos Univ Med J 2013;13(03):359-367

9 Muchukota D, Muchukota D, Manasa Rekha D, Mounika P, Mathappan D. A cross sectional study on knowledge, attitude \& practice towards personal hygiene in women with urinary tract infection and providing patient counselling in ESI hospital, Bangalore. Asian Journal of Hospital Pharmacy. 2020;01(01): 25-29

10 Vijayan A, Inamdhar S, Gowda MRN, et al. An interventional study on knowledge, attitude \& practice towards urinary tract infection among adolescent girls students in selected girls schools in Chitradurga City. Indo American Journal of Pharmaceutical Research. 2018;8(01):1146-1150

11 Eshwarappa M, Dosegowda R, Aprameya IV, Khan MW, Kumar PS, Kempegowda P. Clinico-microbiological profile of urinary tract infection in south India. Indian J Nephrol 2011;21(01):30-36

12 Wagenlehner F, Wullt B, Ballarini S, Zingg D, Naber KG. Social and economic burden of recurrent urinary tract infections and quality of life: a women web-based study (GESPRIT). Expert Rev Pharmacoecon Outcomes Res 2018;18(01):107-117

13 Bodhare TN, Valsangkar S, Bele SD. An epidemiological study of urinary incontinence and its impact on quality of life among women aged 35 years and above in a rural area. Indian J Urol 2010;26(03):353-358
14 Saji N, Amrutha C, Varkey J. Effectiveness of structured teaching programme on prevention of UTI among adolescent girls. International Journal of Science and Health Care Research 2018;3(03): 01-06

15 Ahmed N, Khresheh R. Impact of instructional program about prevention of UTI recurrence on the level of knowledge and selfcare behaviors among women with UTI in Saudi Arabia. IOSR J Nurs Health Sci 2016;5(03):43-51

16 Minardi D, d'Anzeo G, Cantoro D, Conti A, Muzzonigro G. Urinary tract infections in women: etiology and treatment options. Int J Gen Med 2011;4:333-343

17 Das A, Banerjee T. Prevalence of urinary tract infections and susceptibily pattern of uropathogens in women of reproductive age group from North India. J Adv Med 2015;4(1 and 2):5

18 Kodikara H, Seneviratne H, Kaluarachchi A, Corea E. Diagnostic accuracy of nitrite dipstick testing for the detection of bacteriuria of pregnancy. Public Health 2009;123(05): 393-394

19 Millar LK, Wing DA, Paul RH, Grimes DA. Outpatient treatment of pyelonephritis in pregnancy: a randomized controlled trial. Obstet Gynecol 1995;86(4 Pt 1):560-564

20 Mangai MJ, Gaknung B, Hosea G, et al. Assessment of knowledge and prevention practices of urinary tract infection (UTI) among female students residence in university of Jos. International Research Journal of Public and Environmental Health 2019;6(05):89-96

21 Hill JB, Sheffield JS, McIntire DD, Wendel GD Jr. Acute pyelonephritis in pregnancy. Obstet Gynecol 2005;105(01): $18-23$ 